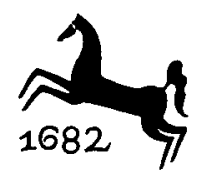

Germanistische AbHandlungen

Das Deutsche KunstMÄrCHEN

Des zWANZIGSTEN Jahrhunderts 
JENS TISMAR

\section{Das deutsche Kunstmärchen des zwanzigsten Jahrhunderts}


GERMANISTISCHE ABHANDLUNGEN 51

CIP-Kurztitelaufnahme der Deutschen Bibliothek

Tismar, Jens:

Das deutsche Kunstmärchen des zwanzigsten

Jahrhunderts / Jens Tismar. - Stuttgart:

Metzler, 1981.

(Germanistische Abhandlungen; 51)

ISBN 978-3-476-00479-6

NE: GT

ISBN 978-3-476-00479-6

ISBN 978-3-476-03155-6 (eBook)

DOI 10.1007/978-3-476-03155-6

(C) 1981 Springer-Verlag GmbH Deutschland

Ursprünglich erschienen bei J.B. Metzlersche Verlagsbuchhandlung und Carl Ernst Poeschel Verlag GmbH in Stuttgart 1981 
FÜR ILSE

Ein alter, hingesunkener Traum wurde wieder lebendig, eine düstere, verdrießliche, müde Schauermär verwandelte sich in freundliches, entzückendes, lebendiges Leben. Bildung und Wissenschaft, Geselligkeit, Geschmack und die übermütigen Künste fingen wieder an sich frei zu entfalten, und das ganze umliegende Land erwachte wie aus langer, langer Trauer. Eine Welt war befreit! Im Park sangen und trällerten wieder die Vögel. Der Druck war gehoben, und die Fessel lag am Boden. Dichtung, Musik und Malerei und das Handwerk reichten sich Sinn, Geist und Hand, um das gesellige Leben am wiedererwachten königlichen Hof zu vergolden und zu verschönen. Der Himmel lachte wieder blau; majestätische Alpengipfel waren entschleiert. Der graue Vorhang hatte sich aufgelöst; finsternisverbreitende Wolken verschwanden; Bäume grünten und blühten; Handel und Wandel ergossen sich mit gefälliger Manier durch das weite, belebte Land.

Robert Walser Dornröschen 


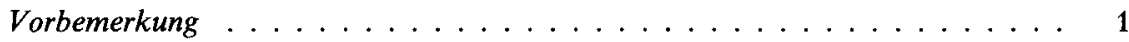

1. Zur Geschichte des Kunstmärchens im 19. Jahrhundert

Reflexionen des Märchens in der Form des Märchens

Peter Kling: "Das Mährlein" . . . . . . . . . . . . . . . . . . . 3

Wilhelm Hauff: "Märchen als Almanach" . . . . . . . . . . . . . . . . 9

Ludwig Bechstein: "Des Märchens Geburt" . . . . . . . . . . . . . . . . . . . . 12

Hans Christian Andersen: "Die Irrlichter sind in der Stadt, sagte die Moorfrau" und $"$ Die Dryader . . . . . . . . . . . . . . . . . . . . 16

Zusammenfassung und Ausblick .................... 26

2. Kunstmärchen zwischen 1914 und 1933

Ödön von Horváth

Hoffnung im Moment der Illusion $\ldots \ldots \ldots 33$

Robert Walser

Der fadenscheinige Zauber . . . . . . . . . . . . . . . . 38

Hermann Hesse

Märchen als Heilmittel $\ldots \ldots \ldots \ldots \ldots \ldots \ldots$. . . . . . . . . . 47

Kurt Schwitters

Helden in schiefer Lage . . . . . . . . . . . . . . . . . . . 57

Tendenzen der Märchenliteratur zwischen 1914 und $1933 \ldots \ldots$. . . . . . 64

3. Kunstmärchen zwischen 1933 und 1945

Hermann Stehr

Das völkische Charisma des Helden . . . . . . . . . . . . . . . . . . . 74

Hans Friedrich Blunck

Ursprünge statt Ursachen gesucht $\ldots \ldots \ldots \ldots \ldots \ldots$. . . . . . . . . . 81

Tendenzen der Märchenliteratur zwischen 1933 und $1945 \ldots \ldots$. . . . . . . 88

4. Kunstmärchen seit 1945

Ernst Wiechert

Rückhalt im Schön-Einfachen . . . . . . . . . . . . . . . . . . . . 99

Wolfgang Hildesheimer

Gegen überkommene Erwartungen . . . . . . . . . . . . . . . . . 107 
Christoph Meckel

Verkehrung ins Groteske . . . . . . . . . . . . . . . . . . . . . 112

Helmut Heißenbüttel

Das Wunderbare in der Montage . . . . . . . . . . . . . . . . . 120

Tendenzen der Märchenliteratur seit $1945 \ldots \ldots \ldots$. . . . . . . . . . 133

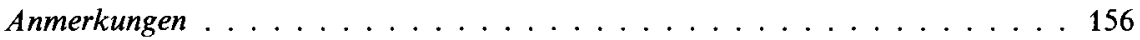

Literaturverzeichnis . . . . . . . . . . . . . . . . . . . 187

Personenregister . . . . . . . . . . . . . . . . . . . 194

Titelregister ....................... 200 
Das Wort >Kunstmärchen` hat einen romantischen Klang. Er ruft eine Reihe rätselvoller, bizarrer, tiefsinniger Erzählungen von Tieck und E. T. A. Hoffmann, Novalis oder Brentano in Erinnerung. Vielleicht auch Erzählungen von Hauff, Storm und Keller, wohl kaum von Autoren des 20. Jahrhunderts. Den hohen Anspruch, der offenbar mit dem Begriff Kunstmärchen verbunden ist, scheinen allein solche Erzählungen einzulösen, die künstlerisch herausragen oder die Märchenfabulieren mit Kunstreflexion verbinden. Dies nun wäre ein Mißverständnis. In Abgrenzung von Volksmärchen, die anonymer Herkunft und in verschiedenen Varianten mündlich tradiert sind, werden Kunstmärchen die Märchen genannt, die einen bestimmten Verfasser haben und in ihrer eigentümlichen Gestalt schriftlich festgehalten wurden. So verstanden, eröffnet sich eine längere Geschichte dieser Gattung, in Europa deutlich konturiert seit der Renaissance: von Straparola über Basile, Perrault, Wieland, Musäus und Goethe bis zu den deutschen Romantikern und Realisten. Und selbst im 20. Jahrhundert gibt es nicht wenige Autoren, die Märchen geschrieben haben, Hesse zum Beispiel oder Wiechert. Merkwürdig an Kunstmärchen ist, daß sie in der Epoche, in der man sie hervortreten sieht, keine selbständige Gattung bilden. Die Märchen von Straparola und Basile sind Interpretationen des Volksmärchen-Musters in der eigenwilligen Gestaltung und aus dem gesellschaftlichen Bewußtsein dieser Autoren. Das läßt sich verallgemeinern: Das Kunstmärchen stellt den Versuch dar, das ahistorische Volksmärchen in der jeweiligen historischen Gegenwart auszulegen. Doch nicht so, daß das Kunstmärchen jeweils von neuem spontan das Volksmärchen-Muster aktualisiert. Es bildet, indem es sich an den bereits vorhandenen Beispielen solcher Interpretation orientiert, eine eigene Tradition aus, auf die es sich berufen kann. In dieser zweifachen Ausrichtung liegt das Besondere: Das Volksmärchen scheint ständig frisch parat, wenn sich das Kunstmärchen in literarischen Innovationen erschöpft hat. Doch näher besehen, ist in neuerer Zeit auch das Volksmärchen, als Buchmärchen, nicht unmittelbar, sondern in historischer Vermittlung gegenwärtig. Wenn sich deutsche Leser und Autoren an den Märchentonfall erinnern, dürften sie zumeist Wendungen aus Grimms Märchen im Ohr haben. Es kommt ein Drittes hinzu: Kunstmärchen sind nicht allein auf das Volksmärchen-Muster und auf die eigene literarische Tradition bezogen; sie sind auch bestimmt durch populäre Ansichten dessen, was ein »Märchen« ausmacht: daß Wünsche erfüllt werden und daß wieder ins Lot kommt, was zur Zeit verquer oder mangelhaft erscheint. Diese Vorstellungen von einem »Märchen« sind nicht an eine bestimmte Art von Erzählung gebunden. Man findet sie auch in Dramen und Gedichten, im Film oder im Roman. Und sie ändern sich mit den gesellschaftlichen Bedingungen. 
Nun läßt sich nicht übersehen: Die Gattung Kunstmärchen hat im 20. Jahrhundert an Bedeutung verloren. Nicht allein, was die Menge der Erzählungen, auch was ihre Stellung unter den literarischen Ausdrucksmöglichkeiten betrifft. Die meisten Kunstmärchen des 20. Jahrhunderts tragen den Zweifel ihrer Autoren in sich, ob diese Gattung noch taugt, gegenwärtige Probleme in einer den Widersprüchen der Zeit angemessenen Weise darzustellen. Der Zweifel äußert sich in verschiedener Form: im parodistischen Spiel mit vertrauten Volks- und Kunstmärchen oder in einer Travestie der Märchenordnung, etwa darin, daß über das bekannte Ende des Märchens hinaus weiter erzählt wird, als ob ein versöhnender Schluß nicht mehr hingenommen werden dürfte. Eine Geschichte der Gattung, die am Zustand ihrer Überalterung und Auflösung einsetzt, erhofft sich aus den Analysen eben der zerbröckelnden Formen Einblick in den Wandel ihrer geschichtlichen Funktionen, Einblick auch in die Veränderungen der persönlichen und gesellschaftlichen Wunschvorstellungen. Zu diesem Zustand der Auflösung ist es nicht von ungefähr gekommen. An einigen Etappen im 19. Jahrhundert kann man die Veränderungen beobachten. Diese Vorgeschichte läßt sich in einem Binnenraum der Gattung ablesen: an Kunstmärchen, die in der eigenen Form reflektieren, von welcher Art das Märchen sei, was es leisten soll und an welchem gesellschaftlichen Ort ihm ein Platz zugedacht ist. Die Geschichte des deutschen Kunstmärchens im 20. Jahrhundert setzt mit der Zäsur des Ersten Weltkriegs ein. Daß er eine Zäsur auch in der Märchenliteratur bedeutet, geben verschiedene Anthologien dieser Jahre zu erkennen. Die zusammenfassenden Kapitel über solche Märchensammlungen wollen über die Analyse markanter Einzelbeispiele hinaus allgemeinere Tendenzen in der Märchenliteratur des jeweiligen historischen Abschnitts verdeutlichen. 